\title{
Carbon Flux as a Measure of Prostate Cancer Aggressiveness: $\left[{ }^{11} \mathrm{C}\right]$-Acetate PET/CT
}

 \\ Häggman², Gunnar Antoni' ${ }^{3}$, Jos Buijs ${ }^{5}$, Irina Velikyan1, and Jens Sörensen ${ }^{1,6}$ \\ 1. Division of Nuclear Medicine and PET, Department of Surgical Sciences, Uppsala University, Uppsala, Sweden \\ 2. Division of Urology, Department of Surgical Sciences, Uppsala University, Uppsala, Sweden \\ 3. Division of Molecular Imaging, Department of Surgical Sciences, Uppsala University, Uppsala, Sweden \\ 4. Medical Physics, Uppsala University Hospital, Uppsala, Sweden \\ 5. Department of Immunology, Genetics and Pathology, Uppsala University, Uppsala, Sweden \\ 6. PET Centre, Uppsala University Hospital, Uppsala, Sweden \\ *These authors contributed equally to this work \\ $\square$ Corresponding author: Naresh Regula, MBBS, PhD student at Uppsala University, Sweden, Tel: +46765647494; E-mail: naresh.regula@surgsci.uu.se
}

(1) The author(s). This is an open access article distributed under the terms of the Creative Commons Attribution License (https://creativecommons.org/licenses/by/4.0/). See http://ivyspring.com/terms for full terms and conditions.

Received: 2019.10.22; Accepted: 2019.12.12; Published: 2020.01.14

\begin{abstract}
Purpose: Dynamic [ ${ }^{1} \mathrm{C}$ ]-acetate positron emission tomography (PET) can be used to study tissue perfusion and carbon flux simultaneously. In this study, the feasibility of the quantification of prostate cancer aggressiveness using parametric methods assessing [ $\left.{ }^{1} \mathrm{C}\right]$-acetate kinetics was investigated in prostate cancer subjects. The underlying uptake mechanism correlated with $\left[{ }^{11} \mathrm{C}\right]$-acetate influx and efflux measured in real-time in vitro in cell culture.

Methods: Twenty-one patients with newly diagnosed low-to-moderate risk prostate cancer underwent magnetic resonance imaging (MRI) and dynamic $\left[{ }^{1} \mathrm{C}\right]$ ]-acetate PET/CT examinations of the pelvis. Parametric images of $\mathrm{K}_{1}$ (extraction $\times$ perfusion), $\mathrm{k}_{2}$ (oxidative metabolism) and $\mathrm{V}_{\mathrm{T}}\left(=\mathrm{K}_{1} / \mathrm{k}_{2}\right.$, anabolic metabolism defined as carbon retention) were constructed using a one-tissue compartment model with an arterial input function derived from pelvic arteries. Regions of interest (ROIs) of the largest cancer lesion in each patient and normal prostate tissue were drawn using information from MRI (T2 and DWI images), biopsy results, and post-surgical histopathology of whole prostate sections $(n=7)$. In vitro kinetics of [ $\left.{ }^{1} \mathrm{C}\right]$-acetate were studied on DU145 and PC3 cell lines using LigandTracer ${ }^{\circledR}$ White equipment for the measurement of the radioactivity uptake in real-time at $37^{\circ} \mathrm{C}$.

Results: Mean prostate specific antigen (PSA) was $8.33 \pm 3.92 \mathrm{ng} / \mathrm{mL}$ and median Gleason Sum 6 (range 5-7). $\mathrm{K}_{1}$, $V_{T}$ and standardized uptake values (SUVs) were significantly higher in cancerous prostate tissues compared to normal ones for all patients $(p<0.001)$, while $k_{2}$ was not $(p=0.26)$. PSA values correlated to early SUVs $(r=0.50$, $p=0.02)$ and $K_{1}(r=0.48, p=0.03)$. Early and late SUVs correlated to $V_{T}(r>0.76, p<0.001)$ and $K_{1}(r>0.64$, $\mathrm{p}<0.005)$. In vitro studies demonstrated higher extraction and retention $(\mathrm{p}<0.01)$ of $\left[{ }^{11} \mathrm{C}\right]$-acetate in the more aggressive PC3 cells.

Conclusion: Parametric images could be used to visualize the $\left[{ }^{11} \mathrm{C}\right]$-acetate kinetics of the prostate cancer exhibiting elevated extraction associated with the cancer aggressiveness. The influx rate of $\left[{ }^{11} \mathrm{C}\right]$-acetate studied in cell culture also showed dependence on the cancer aggressiveness associated with elevated lipogenesis. Dynamic $\left[{ }^{11} \mathrm{C}\right]$-acetate/PET demonstrated potential for prostate cancer aggressiveness estimation using parametric-based $K_{1}$ and $V_{T}$ values.
\end{abstract}

Key words: carbon-11 acetate, positron emission tomography, prostate cancer, dynamic imaging

\section{Introduction}

Prostate cancer (PCa) is one of the most common malignancies in men with an estimated global number of new cases of 1,111,700 and an estimated mortality of 307,000 men per year [1]. The typical methods for monitoring patients with assumed low-risk tumors are measurements of serum prostate specific antigen (PSA) level, repeated prostate biopsies, and magnetic resonance imaging (MRI) $[2,3]$. Patient stratification 
based solely on PSA level is controversial due to the high rate of overdiagnosis, and subsequent unnecessary prostate biopsy and surgery. MRI reduces the risk for the overdiagnosis and is the most robust morphological imaging modality with high predictive capacity in the management of PCa [4]. However, the introduction of diagnostic imaging methods that would allow for quantification of the PCa progression on a molecular level could lead the patient management to the level of personalized medicine. It is of great importance especially in the case of indolent PCa.

Three main metabolic distinctive features in a cancerous cell are: avid glucose consumption (aerobic glycolysis); high energy consumption to drive increased protein and DNA synthesis; and an increased de novo fatty acid (FA) synthesis. In PCa, an increase in aerobic glycolysis is only found in advanced disease, whereas de novo FA synthesis and high energy consumption are common features of both primary and advanced PCa [5]. Like any other cancer cell type, PCa cells show great demand of cell membrane lipids for growth and proliferation [6].

Selective targeting of distinguishing features of cancer cells is the new strategy in molecular cancer therapeutics. Fatty acid synthetase (FASN), the rate limiting enzyme in de novo FA synthesis, converting excess carbon intake into fatty acids for storage, seems to be an attractive potential target for new therapeutic approach [5]. Though, several FASN inhibitors had showed antitumor activity, their mechanism is still not well understood. Moreover, large variations in FASN expression levels in individual tumors pose a challenge to predict therapeutic outcome. To avoid unnecessary treatment, methods to stratify those who gain benefit with the application of FASN targeted therapy are needed.

One approach to this requirement is focusing on the quantification of the uptake of radiolabeled acetate $\left(\left[{ }^{11} \mathrm{C}\right]\right.$-acetate $)$ using positron emission tomography (PET). Acetate, as an important intermediary substrate, is the main carbon source for fatty acid and lipid synthesis [7]. The intracellular fate of acetate is diverse. To use acetate, cells must activate it into acetyl-CoA which is regulated by acetyl-CoA synthetase (AceCS). Two distinctive forms of mammalian AceCS enzymes are identified and are localized over mitochondria and cytosol [8]. Acetate entering the mitochondria, under the regulation of mitochondrial AceCS and other enzymes, is metabolized to $\mathrm{CO}_{2}$ and leaves the cell reflecting the oxidative metabolism. This pathway has been exploited with $\left[{ }^{11} \mathrm{C}\right]$-acetate PET combined with computed tomography (CT) to quantify the myocardial oxidative metabolism [9-14]. Whereas cancerous cells govern the use of acetate for de novo lipogenesis wherein FASN is the rate limiting enzyme.

Previous studies showed that an increase in FA synthesis seems to be an early event in tumorigenesis and is correlated with the progression of the disease. Preclinical in vitro and in vivo studies have demonstrated a correlation of $\left[{ }^{11} \mathrm{C}\right]$-acetate uptake with enhanced FASN [15-17] and cytosolic AceCS [18] expression. Moreover, a clinical study in 123 consecutive patients showed that FASN was upregulated in PCa and its expression was correlated to tumor aggressiveness in terms of $\left[{ }^{11} \mathrm{C}\right]$-acetate accumulation [19]. These studies proved $\left[{ }^{11} \mathrm{C}\right]$-acetate PET/CT to be a promising metabolic tracer for primary staging and for localizing recurrent disease. Moreover, $\left[{ }^{11} \mathrm{C}\right]$-acetate PET/CT was found superior to ${ }^{18} \mathrm{~F}-\mathrm{FDG}$ PET/CT in terms of sensitivity [20] and identical to ${ }^{18} \mathrm{~F}$-choline PET/CT in terms of detection rate and uptake intensity [21]. Regula et al. have shown that the standardized uptake value (SUV) along with PET volumetrics of $\left[{ }^{11} \mathrm{C}\right]$-acetate PET/CT serve as predictors of survival in biochemical recurrent $\mathrm{PCa}$ patients after surgery [22]. However, SUV does not explain the underlying tumor biology completely, and the preclinical studies linking radiolabeled acetate uptake with FASN expression failed to show the dynamic changes occurring with the consumed acetate at the cell level. Contrary to SUV, parametric images of $\left[{ }^{11} \mathrm{C}\right]$-acetate kinetics based on dynamic PET data can show perfusion and oxidative metabolism at the voxel level.

The significance of perfusion and tumor oxidative metabolism in cancer growth inhibition was demonstrated clinically proving the potential of non-invasive $\left[{ }^{11} \mathrm{C}\right]$-acetate PET/CT imaging for the investigation of bioenergetic mechanisms of prostate cancer [23]. Yoshii et al. showed in their experimental work that inhibition of FASN reduces the tumor activity in terms of $\left.{ }^{[11} \mathrm{C}\right]$-acetate uptake [18]. More fundamental understanding of the role of perfusion, oxidative and anabolic metabolism of PCa would potentially improve the accuracy of tumor diagnosis and prediction of treatment outcome. The investigation of $\left[{ }^{11} \mathrm{C}\right]$-acetate uptake mechanism and role of perfusion and metabolism can be aided by kinetic modelling based on dynamic scanning of the patients. In particular, the overall $\left[{ }^{11} \mathrm{C}\right]$-acetate uptake could be well described by a 3-compartment model [24], however fundamental studies of separate aspects of the uptake process require further studies employing respective kinetic models and clear correlation of the results with in vitro experiments designed to reveal the mechanism of the particular aspects. 
The aim of this study was, therefore, to investigate the tumor biology using single-tissue compartment model derived parametric images of $\left[{ }^{11} \mathrm{C}\right]$-acetate dynamic PET/CT and to correlate the results with $\left[{ }^{11} \mathrm{C}\right]$-acetate dynamic data from cell experiments revealing the metabolic activity in real-time.

\section{Materials and Methods}

\section{Dynamic [ $\left.{ }^{11} \mathrm{C}\right]$-acetate Clinical setting}

\section{Patients}

Twenty-one patients with newly diagnosed and biopsy proven low-to-moderate risk prostate cancer were included in this prospective study and were scanned between the end of 2009 and the beginning of 2011. Mean age was $65 \mathrm{y}$ (range, $51-75 \mathrm{y}$ ). PSA at the time of PET was $8.33 \pm 3.92 \mathrm{ng} / \mathrm{mL}$. Median Gleason score of the subjects was 6 (range, 5-7). Pelvic magnetic resonance imaging (MRI) with different sequences such as T2-weighted and diffusion-weighted was performed in all patients prior to dynamic PET/CT. Seven of 21 patients underwent surgery and the resected prostate gland was sent for histopathology.

Ethical approval for this prospective study was obtained from the Regional Ethics Committee (EPN 2009/191) and all patients signed informed consent before inclusion.

\section{PET/CT protocol}

$\left[{ }^{11} \mathrm{C}\right]$-acetate was synthesized according to the $\left[{ }^{11} \mathrm{C}\right]$-acetate simple synthesis method proposed by Le Bars et al. [25] based on original synthesis [26] with in-house modifications. After a $6 \mathrm{~h}$ fast to avoid any variation in the measurement due to the influence of food intake, all patients underwent a dynamic PET scan starting simultaneously with intravenous injection of $5 \mathrm{MBq} / \mathrm{kg} \quad\left[{ }^{11} \mathrm{C}\right]$-acetate. PET was performed using a GE Discovery ST16 scanner (GE Healthcare, Waukesha, WI) with a spatial resolution of $5 \mathrm{~mm}$ at the center of the field of view. Thirty-two frames were acquired of $12 \times 5 \mathrm{~s}, 6 \times 10 \mathrm{~s}, 4 \times 30 \mathrm{~s}, 4 \times 60 \mathrm{~s}$, $2 \times 120 \mathrm{~s}$, and $4 \times 300 \mathrm{~s}$ duration. Prior to PET, a CT transmission scan $(140 \mathrm{kV}, 40-80 \mathrm{~mA})$ without contrast medium was obtained.

PET images were reconstructed using ordered subsets expectation maximization (OSEM) using 2 iterations and 21 subsets, applying all appropriate corrections.

\section{Image processing}

PET/CT images were analysed using VOIager (GE Healthcare, Uppsala, Sweden). Volume of interests (VOIs) were drawn over iliac vessels and time activity curves (TAC) were extracted which served as an arterial input function for the kinetic model. Early (2-5 min) and late (22-32 min) standardized uptake value (SUV) images were derived from dynamic PET and analysed.

\section{Kinetic Model}

$\left[{ }^{11} \mathrm{C}\right]$-acetate kinetics were modelled using a single-tissue compartment model, which explains how $\left[{ }^{11} \mathrm{C}\right]$-acetate is transported across the cell membrane and a fraction undergoes oxidative metabolism by entering the Krebs cycle, while the remaining is added to the intracellular metabolic pool and used further in anabolic metabolism.

A basis-function implementation of the single-tissue compartment model as shown in Figure 1 yielded parametric images of $K_{1}, k_{2}$ and $V_{T}$. $K_{1}$ indicates the transport rate of $\left[{ }^{11} \mathrm{C}\right]$-acetate into prostate which is the product of extraction and perfusion $\left(\mathrm{mL} / \mathrm{cm}^{3} / \mathrm{min}\right)$ and $\mathrm{k}_{2}$ denotes the rate of oxidative metabolism $\left(\mathrm{min}^{-1}\right)$. $\mathrm{V}_{\mathrm{T}}$ reflects the amount of $\left[{ }^{11} \mathrm{C}\right]$-acetate volume distributed within prostate tissue used for anabolic metabolism $\left(\mathrm{mL} / \mathrm{cm}^{3}\right)$. Correction for the metabolic stability of $\left[{ }^{11} \mathrm{C}\right]$-acetate was applied as previously described [24]. A 6-mm filter was applied for smoothing of the $\mathrm{k}_{2}$ parametric image.



Figure 1. Simple one tissue compartment model describing the kinetics of [' 'C]-acetate in a prostate cancer cell. $\mathrm{K}_{\mathrm{I}}$ reflects the extraction rate of [' $\left.{ }^{\prime} \mathrm{C}\right]$-acetate into prostate cell and $\mathrm{k}_{2}$ indicates the fraction that undergoes oxidative metabolism in mitochondria and leaves the cell as ${ }^{\prime \prime} \mathrm{CO}_{2}$. The remaining [" $\left.\mathrm{C}\right]$-acetate is distributed $\left(\mathrm{V}_{\mathrm{T}}\right)$ within the prostate cell used for anabolic metabolism. TCA: mitochondrial Krebs cycle. 
From the histopathology report $(\mathrm{n}=7)$ and based on MRI data, the cancerous region in prostate was differentiated from normal tissue and separate region of interests (ROIs) were drawn over these areas on parametric images for the subsequent analysis.

\section{In vitro dynamic [ $\left.{ }^{\prime \prime} \mathrm{C}\right]$-acetate}

The human prostate cancer cell lines DU145 and PC3 (ATCC, Germany) were used in the cell experiments. Cells were cultured in RPMI medium supplemented with $10 \%$ fetal calf serum, $2 \mathrm{mM}$ L-glutamine and PEST (penicillin $100 \mathrm{IU} / \mathrm{mL}$ and 100 $\mu \mathrm{g} / \mathrm{mL}$ streptomycin) (Biochrom AG). DU145 and PC3 cells were seeded on a local area of a cell culture dish. The cells were incubated overnight, and they formed a confluent layer of cells by the time of the experiment (NunclonTM, Size 100620, NUNC A/S, Roskilde, Denmark). The uptake and retention of $\left.{ }^{[11} \mathrm{C}\right]$-acetate in living cells was monitored in real-time at $37^{\circ} \mathrm{C}$ using LigandTracer ${ }^{\circledR}$ White (Ridgeview Instruments $\mathrm{AB}$, Uppsala, Sweden) placed in an incubator $[27,28]$. The cell culture dish was placed on an inclined rotating support. The radioactivity detection unit was above the upper part of the dish and the inclination ensured that the $3 \mathrm{~mL}\left[{ }^{11} \mathrm{C}\right]$-acetate containing medium was mainly outside the detection area. During each full rotation, the signal from the cell and a reference area was recorded. The reference signal was automatically subtracted and corrected for $\left.{ }^{[11} \mathrm{C}\right]$ decay resulting in a real-time signal that represented cell associated $\left[{ }^{11} \mathrm{C}\right]$-acetate both during incubation and after the wash. For experiments where the acetate uptake was linear, the relative acetate uptake rate was quantified by dividing the uptake rate, i.e. the decay corrected signal increase per min, by the average signal derived from the reference area during incubation which provided a relative measure of the amount of $\left[{ }^{11} \mathrm{C}\right]$-acetate added to the dish.

\section{In vitro kinetics evaluation of [ $\left.{ }^{11} \mathrm{C}\right]$-acetate}

In a kinetic assay, the $\left[{ }^{11} \mathrm{C}\right]$-acetate uptake and retention rates by PC3 and DU145 cell lines were evaluated under the same conditions and the experiments were performed in parallel using two LigandTracer ${ }^{\circledR}$ devices. The uptake of $\left[{ }^{11} \mathrm{C}\right]$-acetate by DU145 and PC3 cells was measured for ca. $15 \mathrm{~min}$ after adding $500-2000 \mathrm{kBq}$ of the radiotracer. In a set of experiments, the uptake of $\left[{ }^{11} \mathrm{C}\right]$-acetate was followed up for $120 \mathrm{~min}$ after incubation. Thereafter, the tracer containing solution was replaced with fresh medium, after washing the dish two times with medium. The retention of $\left[{ }^{11} \mathrm{C}\right]$-acetate in the cells was followed for around 30-45 min.

To check the uptake saturability of $\left[{ }^{11} \mathrm{C}\right]$-acetate, two assays were performed where the uptake was monitored over time using LigandTracer ${ }^{\circledR}$. In a titration assay, cells were incubated with increasing concentrations of $\left[{ }^{11} \mathrm{C}\right]$-acetate, selected based on the amount of activity, i.e. 200, 600, 1800, $3000 \mathrm{kBq}$.

In a competition assay, two experiments were performed in parallel on PC3 cells. In both experiments about $1 \mathrm{MBq}$ of $\left[{ }^{11} \mathrm{C}\right]$-acetate was added to PC3 cells and the uptake of $\left[{ }^{11} \mathrm{C}\right]$-acetate was monitored for $15 \mathrm{~min}$. Thereafter, 100 mmoles of acetic acid was added to one of the dishes and the uptake of $\left[{ }^{11} \mathrm{C}\right]$-acetate by PC3 cells was monitored further during up to $100 \mathrm{~min}$.

\section{In vitro [ $\left.{ }^{1} \mathrm{C}\right]$-acetate uptake per cell}

A study was performed in which DU145 and PC3 cells were seeded in 6 petri dishes, i.e., three sets of dishes per cell line. About $3 \mathrm{MBq}\left[{ }^{11} \mathrm{C}\right]$-acetate was added to each dish and incubated at $37^{\circ} \mathrm{C}$ for $15 \mathrm{~min}$. Thereafter, the radioactive solution was removed, and the cells were washed twice with ice-cold serum free medium. Then, the cells were detached by trypsin-EDTA solution (0.25\% trypsin, $0.02 \%$ EDTA in buffer, Biochrom AG, Berlin, Germany). The number of cells were counted, and the amount of the radioactivity was measured using a well-type $\mathrm{NaI}(\mathrm{Tl})$ scintillation counter, applying correction for dead-time and decay.

\section{Statistical analysis}

Data are presented as mean $\pm S D$, unless otherwise stated. Differences between groups were evaluated using Wilcoxon signed-rank test. Correlation studies were conducted using Spearman's rank correlation coefficients. A two-tailed p-value of $<0.05$ was considered statistically significant. Statistical analyses were performed using JMP V12 (SAS Institute Inc., Cary, NC), unless otherwise stated.

\section{Results}

\section{[11C]-acetate dynamic PET in humans}

The clinical characteristics of the study population are shown in Table 1 . The mean age of the study population was 65 years (range $51-75$ years) with mean PSA level of $4.33 \pm 3.92 \mathrm{ng} / \mathrm{mL}$ and median Gleason of 6 (range 5-7).

\section{[ $\left.{ }^{\prime \prime} \mathrm{C}\right]$-acetate uptake pattern}

A typical example of the time activity curve is shown in Figure 2. The lesion tissue curve has an initial incline and reaches a plateau at around 5 mins. Analysis of time activity curves revealed that early uptake (early SUV), from 2 to 5 minutes on average was similar to the late uptake from 22 to 32 minutes (late SUV). 
Table 1. Demographic data on the age, PSA level, Gleason sum and risk assessment of patient cohort. * indicates patients with post-surgical ROls.

\begin{tabular}{lllll}
\hline Patient No. & Age (years) & PSA & Gleason sum & Risk \\
\hline 1 & 65 & 9.2 & 6 & low \\
$2^{*}$ & 67 & 12 & 7 & moderate \\
3 & 72 & 3.2 & 5 & low \\
4 & 62 & 4.6 & 7 & moderate \\
5 & 59 & 6.1 & 6 & low \\
$6^{*}$ & 66 & 3.8 & 6 & low \\
7 & 69 & 10 & 7 & moderate \\
8 & 72 & 12 & 6 & moderate \\
9 & 75 & 13 & 6 & moderate \\
10 & 65 & 5.6 & 6 & low \\
11 & 63 & 11 & 7 & moderate \\
$12^{*}$ & 68 & 4 & 7 & moderate \\
$13^{*}$ & 57 & 11 & 6 & moderate \\
14 & 60 & 7.8 & 6 & low \\
15 & 62 & 17 & 5 & low \\
$16^{*}$ & 69 & 13 & 7 & moderate \\
17 & 74 & 11 & 6 & moderate \\
$18^{*}$ & 64 & 6 & 6 & low \\
19 & 62 & 6 & 5 & low \\
$20^{*}$ & 51 & 4.8 & 6 & low \\
21 & 62 & 3.8 & 5 & low \\
\hline
\end{tabular}

The basis function implementation of the single-tissue compartment kinetic model successfully produced parametric images in all subjects. An example of parametric images is shown in Figure $3 . K_{1}$ and $\mathrm{V}_{\mathrm{T}}$ of cancerous prostate on parametric images showed a significant difference compared with normal prostate.

The parametric values and the SUV from the dynamic scans of both normal and cancerous prostate are summarised in Table 2. No significant difference in oxidative metabolism $\left(\mathrm{k}_{2}\right)$ was noted among different prostate regions.

A Spearman correlation test showed significant correlation of $\mathrm{K}_{1}$ and $\mathrm{V}_{\mathrm{T}}$ with both early and late SUV and values are shown in Table 3 . Bivariate analysis showed correlation of PSA to early SUV ( $\mathrm{r}=0.50$, $\mathrm{p}=0.02)$ and $\mathrm{K}_{1}(\mathrm{r}=0.48, \mathrm{p}=0.03)$.
Table 2. Dynamic [ ${ }^{1} \mathrm{C}$ ]-acetate PET/CT SUV findings along with parametric values in the study population. The data is presented as mean $\pm S D(n=21)$.

\begin{tabular}{llll}
\hline Parameters & Normal prostate & Cancerous prostate & p-value \\
\hline SUV early & $1.99 \pm 0.65$ & $2.99 \pm 0.69$ & $<0.01$ \\
SUV late & $2.08 \pm 0.70$ & $3.04 \pm 0.73$ & $<0.01$ \\
$\mathrm{~K}_{1}\left(\mathrm{ml} / \mathrm{cm}^{3} / \mathrm{min}\right)$ & $0.23 \pm 0.05$ & $0.34 \pm 0.09$ & $<0.01$ \\
$\mathrm{k}_{2}\left(\mathrm{~min}^{-1}\right)$ & $0.05 \pm 0.01$ & $0.04 \pm 0.01$ & 0.26 \\
$\mathrm{~V}_{\mathrm{T}}\left(\mathrm{ml} / \mathrm{cm}^{3}\right)$ & $5.44 \pm 1.52$ & $8.6 \pm 2.52$ & $<0.01$ \\
\hline
\end{tabular}

Table 3. Correlation of parametric values and SUV along with spearman correlation and respective $p$-values.

\begin{tabular}{llll}
\hline \multicolumn{2}{l}{ Correlation comparison } & Spearman $\boldsymbol{\rho}$ & p-value \\
\hline Early SUV & $\mathrm{V}_{\mathrm{T}}$ & 0.76 & $<0.001$ \\
Early SUV & $\mathrm{K}_{1}$ & 0.65 & 0.001 \\
Early SUV & $\mathrm{PSA}$ & 0.5 & 0.02 \\
Late SUV & $\mathrm{V}_{\mathrm{T}}$ & 0.8 & $<0.001$ \\
Late SUV & $\mathrm{K}_{1}$ & 0.64 & 0.001 \\
$\mathrm{~K}_{1}$ & $\mathrm{~V}_{\mathrm{T}}$ & 0.9 & $<0.001$ \\
\hline
\end{tabular}

\section{In vitro kinetics evaluation of [ $\left.{ }^{11} \mathrm{C}\right]$-acetate}

In a titration assay, it could be seen that [11C]-acetate uptake by DU145 and PC3 cells in vitro was characterized by a steady uptake that was proportional to the acetate concentration (Figure 4).

With the $\left[{ }^{11} \mathrm{C}\right]$-acetate concentrations and incubation times used in the kinetic experiments, [11C]-acetate uptake was linear and proportional to the $\left[{ }^{11} \mathrm{C}\right]$-acetate concentration in solution. The retention of $\left[{ }^{11} \mathrm{C}\right]$-acetate in the cells was at least 45 min as demonstrated by the insignificant decrease of the $\left[{ }^{11} \mathrm{C}\right]$-acetate signal when $\left[{ }^{11} \mathrm{C}\right]$-acetate incubation solution was substituted with fresh media solution (Figure 4). The relative uptake rate of $\left[{ }^{11} \mathrm{C}\right]$-acetate (mean $\pm \mathrm{SD}, \mathrm{n}=5$ ) was $0.72 \pm 0.24 \mathrm{~h}^{-1}$ for DU145 cells and $2.94 \pm 0.12 \mathrm{~h}^{-1}$ for PC 3 cells $(\mathrm{p}=0.002)$.

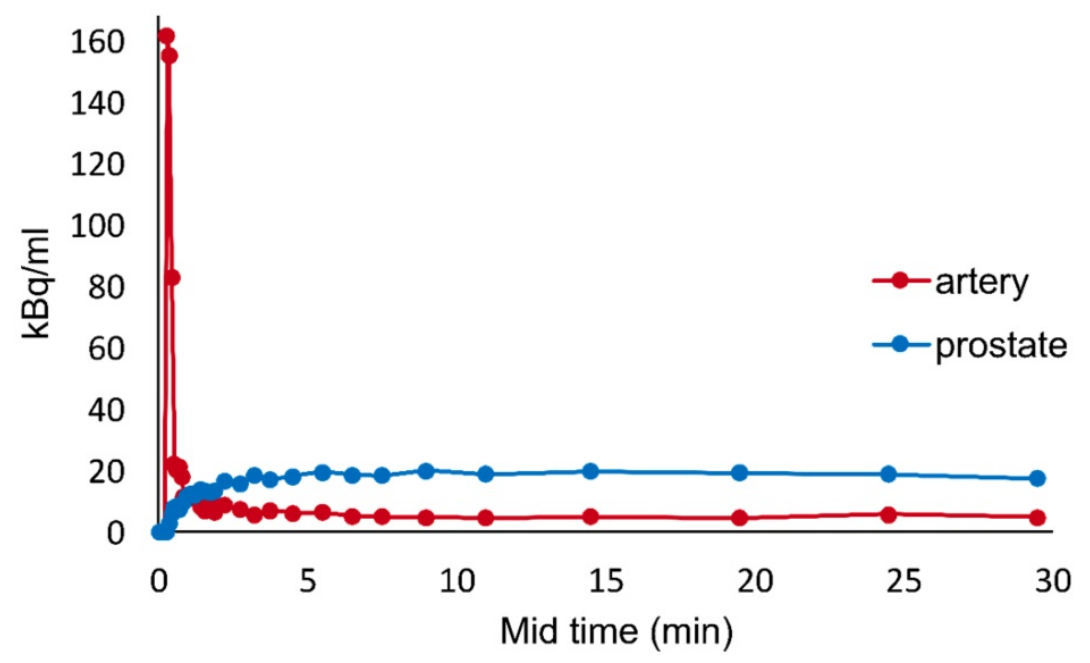

Figure 2. Typical example of time activity curve generated for one of the patients from VOI placed over iliac vessels and prostate tissue. 


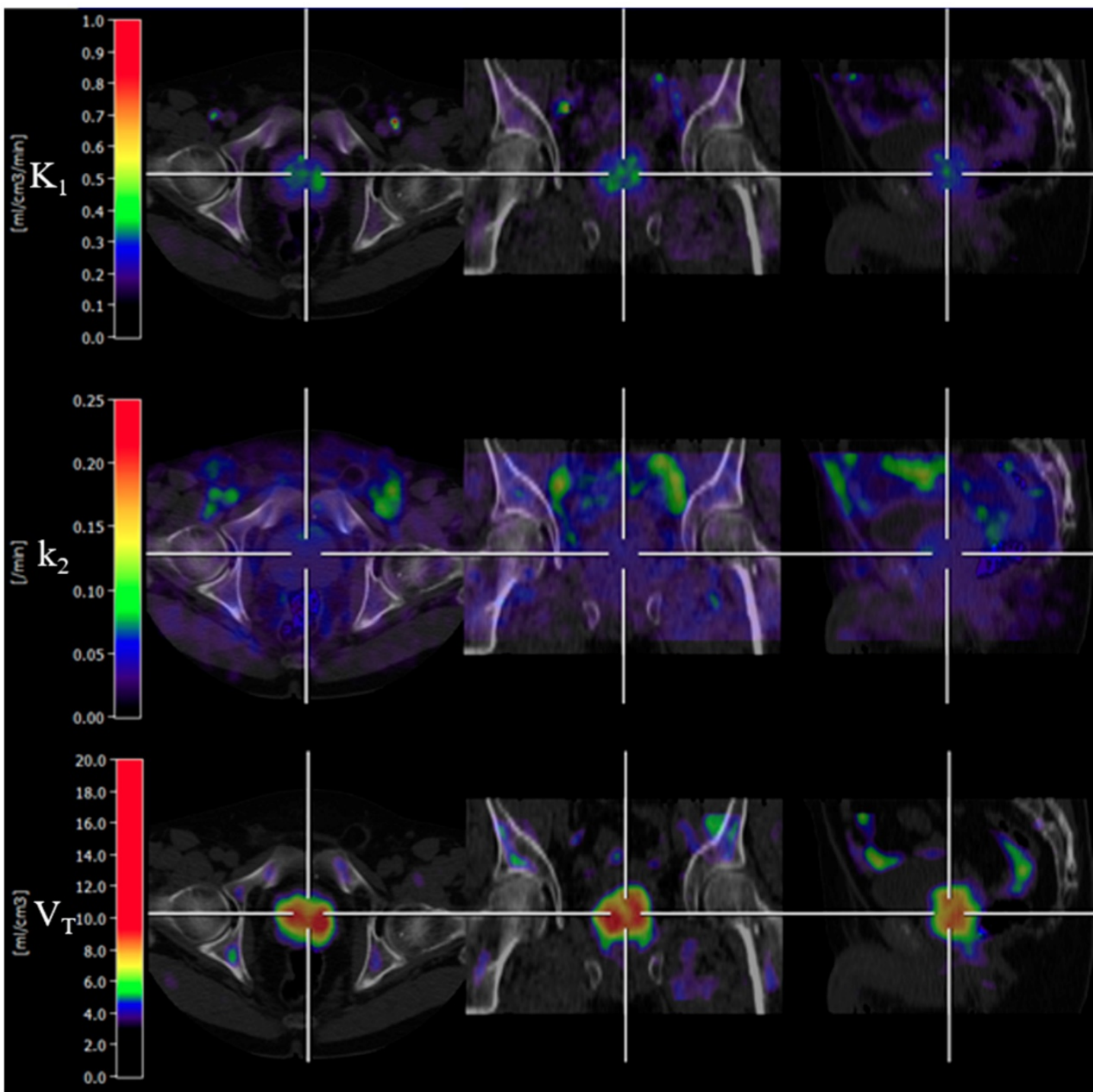

Figure 3. An example of parametric images of $\mathrm{K}_{1}, \mathrm{k}_{2}$ and $\mathrm{V}_{T}$ (Patient 2). $\mathrm{V}_{T}$ parametric image showed bilateral signal uptake in the prostate gland. The first, second and third rows demonstrate trans-axial, coronal and sagittal PET/CT fused images, respectively.



Figure 4. LigandTracer ${ }^{\circledR}$ curve of [ $\left.{ }^{\prime \prime} \mathrm{C}\right]$-acetate uptake and retention on PC3 and DU145 cells. The [' ${ }^{\prime \prime}$ ]-acetate concentration was gradually increased by subsequently adding $200,600,1800$, and $3000 \mathrm{kBq}$ (indicated by the blue arrows), respectively. [" C]-acetate retention was monitored after replacement of the incubation solution with medium after 125 min (indicated by the black arrows). 


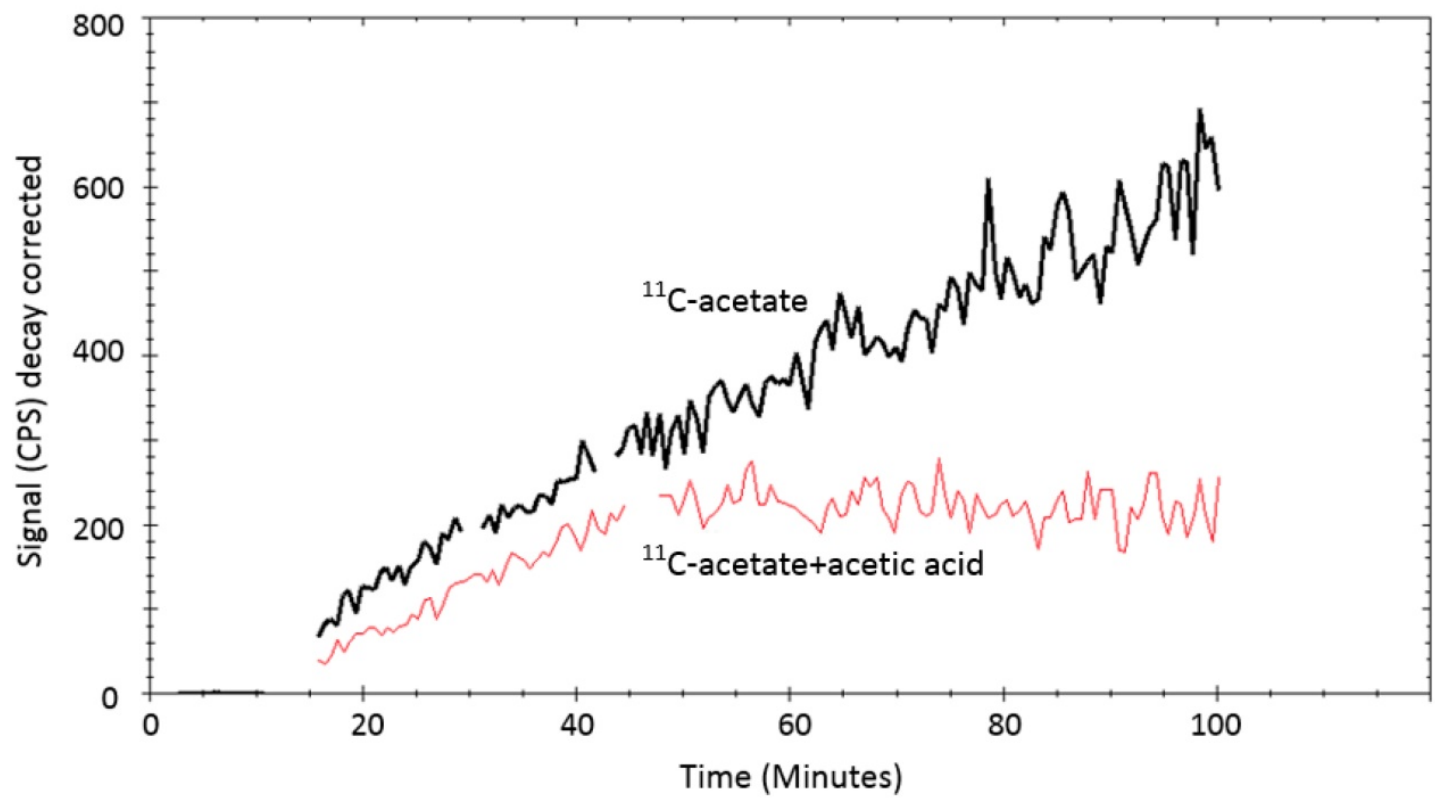


measured for $15 \mathrm{~min}$. Thereafter, 100 mmoles stable (non-labelled) acetic acid was added to one cell dish and the uptake of [" $\left.{ }^{\prime \prime}\right]$-acetate was measured further for up to 100 minutes. The uptake of [ $\left.{ }^{\prime \prime} \mathrm{C}\right]$-acetate reduced considerably in the presence of non-labelled acetic acid.

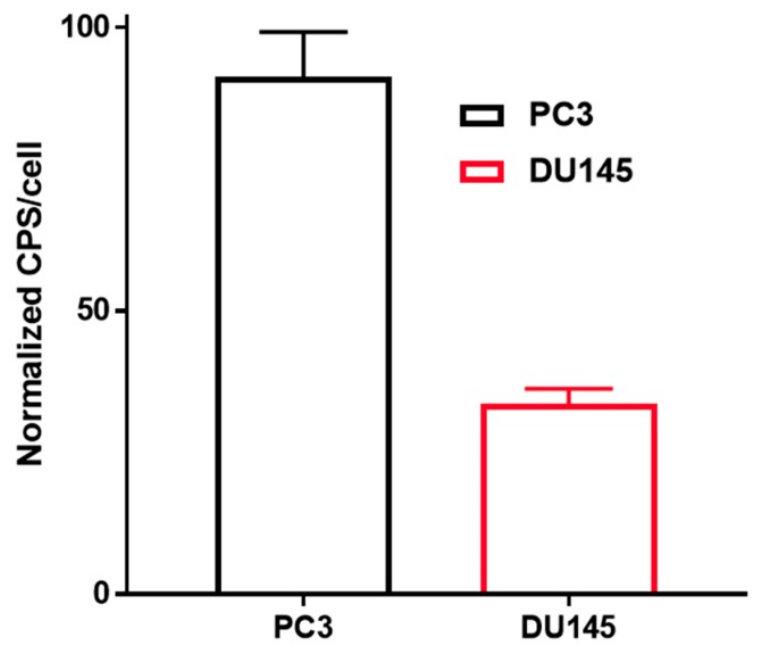

Figure 6. In vitro uptake of [" $\mathrm{C}]$-acetate normalized to the amount of the cells: PC3 (black) and DU145 (red) 15 min after incubation at $37^{\circ} \mathrm{C}$. Results are presented as cps (count per second) per cell (cps/cell), error bars indicate $95 \%$ confidence interval of the mean. Statistically significant difference between cell lines was calculated according to Student's t-test resulting in a p-value of $<0.001$.

Excretion rates (mean $\pm \mathrm{SD}, \mathrm{n}=5$ ) for DU145 and PC3 cells were $0.24 \pm 0.06 \mathrm{~h}^{-1}$ and $0.52 \pm 0.04 \mathrm{~h}^{-1}$, respectively. The $\left[{ }^{11} \mathrm{C}\right]$-acetate uptake was strongly reduced when excess of non-labeled acetate (100 mmoles) was added as seen in Figure 5.

\section{In vitro [ $\left.{ }^{\prime \prime C}\right]$-acetate uptake per cell}

The uptake of [11C]-acetate by PC3 cells (cps/cell: $0.008 \pm 0.001$ ) was about two times higher than that by DU145 cells (cps/cell: $0.003 \pm 0.000$ ) (Figure 6).

\section{Discussion}

In this study, the kinetics of $\left[{ }^{11} \mathrm{C}\right]$-acetate uptake in PCa subjects and prostate cancer cell lines were investigated. $\left.{ }^{11} \mathrm{C}\right]$-acetate has previously been used for whole-body PET/CT imaging in PCa patients in primary staging and to localize the biochemical recurrent lesions in patients after primary treatment [20, 29-33]. In this study, we applied a simple single-tissue compartment model to describe and visualize $\left[{ }^{11} \mathrm{C}\right]$-acetate uptake kinetics with the aim to investigate the underlying uptake mechanism and respective tumor biology. This study demonstrated that the SUV of PCa measured in a human static whole-body image was primarily affected by initial delivery and only to a lesser extent by the clearance. This finding was confirmed by real-time kinetic studies of $\left[{ }^{11} \mathrm{C}\right]$-acetate uptake by standard PCa cell clones in vitro.

\section{['IC]-acetate kinetics and prostate cancer biology}

Localizing the cancerous region over the parametric images was aided by MRI and histopathology documentation. A single-tissue compartment model was successfully used to create parametric images of acetate kinetics (Figure 3). The input function was derived from the iliac vessels using VOI based method since the invasive arterial blood sampling was not feasible due to practical challenges. The metabolic stability correction was conducted to get the best fit between the measured and model derived time activity curves assuming that $\left.{ }^{11} \mathrm{C}\right]$-labelled $\mathrm{CO}_{2}$ in tissue was negligible [24].

In the case of $\left[{ }^{11} \mathrm{C}\right]$-acetate in tracer amounts, $\mathrm{K}_{1}$ equals the nutrient delivery rate and probably reflects perfusion, which is elevated in PCa in proportion to 
tumor aggressiveness [34, 35]. Previously, $K_{1}$ was calculated for primary, recurrent and benign lesions in PCa patients [24], however, comparison with control normal prostate tissue was not conducted. $\mathrm{K}_{1}$ in cancerous regions was determined using singleand two-tissue compartment kinetic models with or without correction for metabolic stability, and the resulting values varied ranging from 0.23 to 0.32 $\mathrm{mL} / \mathrm{cm}^{3} / \mathrm{min}$ dependent on the number of included kinetic parameters [24]. The simplified single-tissue compartment model used in our study resulted in similar value of $0.34 \mathrm{~mL} / \mathrm{cm}^{3} / \mathrm{min}$ in cancerous prostate tissue. It was significantly higher than that in non-cancerous prostate $\left(0.23 \mathrm{~mL} / \mathrm{cm}^{3} / \mathrm{min}\right)$ and correlated with PSA values $(r=0.48, p=0.03)$. The extracted $K_{1}$ values may have been somewhat overestimated due to the incomplete recovery of the arterial blood curve and resulting partial volume effect, but this respective error was likely systematic and hence did not deteriorate the inter-patient comparison. The highest signal in $\left.{ }^{[11} \mathrm{C}\right]$-acetate $\mathrm{K}_{1}$ images correlated with the largest tumor nodule. This observation was confirmed in the cell line study wherein the more aggressive PC3 cells had higher uptake rate than DU145 cells, supporting the view that $\left.{ }^{11} \mathrm{C}\right]$-acetate uptake is an indicator of $\mathrm{PCa}$ growth. Thus, $\left[{ }^{11} \mathrm{C}\right]$-acetate was most probably taken up in proportion to fatty acid synthesis. In vitro kinetics property evaluation of $\left[{ }^{11} \mathrm{C}\right]$-acetate showed that uptake of $\left[{ }^{11} \mathrm{C}\right]$-acetate by DU145 and PC 3 cells was increased continuously over time when the cells were incubated for up to $2 \mathrm{~h}$ (data not shown). No saturation could be observed at any added concentration of $\left[{ }^{11} \mathrm{C}\right]$-acetate (Figure 4) indicating the continuous consumption of the latter by the cells for lipogenesis. Moreover, the uptake rate of $\left[{ }^{11} \mathrm{C}\right]$-acetate was significantly higher in faster growing PC3 cells than that for DU145. This observation is in concordance with previously published results demonstrating higher growth potential of PC3 cells as compared to that of DU145 cells [36]. Thus, faster kinetics of $\left[{ }^{11} \mathrm{C}\right]$-acetate presumably reflect the level of aggressiveness of the cancer cells. The $\left[{ }^{11} \mathrm{C}\right]$-acetate uptake normalized to the cell amount (cps/cell) was almost three-fold higher for PC3 cells than that for DU145 ( $p<0.001$ ) (Figure 6). In addition, the uptake of $\left.{ }^{[11} \mathrm{C}\right]$-acetate decreased substantially when 100 mmoles of acetic acid was added to the cells (Figure 5) indicating the displacement of $\left[{ }^{11} \mathrm{C}\right]$-acetate by the excessive amount of acetic acid participating in the same specific biological process of lipogenesis.

Clearance rate $\left(k_{2}\right.$, Figure 3$)$ of $\left[{ }^{11} \mathrm{C}\right]$-acetate is used as an index for oxidative metabolism when applied in cardiac studies [11, 12,37, 38], but oxidative metabolism in $\mathrm{PCa}$ is less well studied. There is evidence that forcing the cancer cell back into oxidative metabolism can inhibit cancer growth [39]. Active oxidative metabolism in cancer might potentially be studied with dynamic $\left[{ }^{11} \mathrm{C}\right]$-acetate PET. Using a similar technique as in the current study, Sun et al. found an indication that radiation therapy in head and neck cancers (H\&N) with high oxidative metabolism resulted in more complete response [23]. In $H \& N$ the clearance rate was calculated using simple mono-exponential fitting of the wash-out curve, resulting in a slight underestimation of the rates, compared to $\mathrm{k}_{2}$ from the kinetic modelling. Nonetheless, PCa appeared to have much higher rates of oxidative metabolism $\left(0.04 \pm 0.01 \mathrm{~min}^{-1}\right)$ in our study, compared to what was found in $\mathrm{H} \& \mathrm{~N}$ $\left(0.01 \pm 0.001 \mathrm{~min}^{-1}\right)$. For comparison, mean $\mathrm{k}_{2}$ in normal left ventricular myocardium was $0.08 \pm 0.02$ [40]. Post study follow-up showed that 14 out of 21 patients were primarily treated with radical prostatectomy, 1 had radiation therapy (RT) with curative intent, 4 were under active surveillance and 2 patients had no follow-up data. The data does not allow any conclusions on the association between oxidative metabolic rates and RT outcome. No significant difference of $\mathrm{k}_{2}$ between cancerous and normal regions of prostate was found in our study $(p=0.26)$, suggesting that low-intermediate risk $\mathrm{PCa}$ and normal prostate depend on oxidative metabolism to the same extent.

The carbon retained within the cell and used for anabolic metabolism can be quantified by $\mathrm{V}_{\mathrm{T}}$ which is the ratio of perfusion and clearance rates, reflecting the amount of $\left[{ }^{11} \mathrm{C}\right]$-acetate retention within the cell after clearance. In this study, the $V_{T}$ value significantly differed between normal and cancerous prostate regions $(p<0.01)$. From this small study group, it is possible to hypothesize that $\mathrm{V}_{\mathrm{T}}$ might be able to differentiate cancerous region from normal prostate. Like $K_{1}$, the $V_{T}$ value is also influenced by partial volume effect. $\mathrm{V}_{\mathrm{T}}$ was the kinetic parameter with the closest correlation to SUV from static imaging ( $\mathrm{r}=0.8$ for late SUV), confirming that what is measured in clinical whole-body PET/CT images can be used as an estimate of the anabolic metabolism of the tumor at the time of scanning. In addition, the retention of $\left[{ }^{11} \mathrm{C}\right]$-acetate in the cells in vitro was high and in a good agreement with the data obtained from PET images of the studied patients in this study (Figure 2, 4). There was a significant difference $(p=0.001)$ between the retention rates for DU145 and PC3 cell lines indicating that PC3 had a 2 times faster anabolic metabolism than DU145.

The investigation of the correlation of clinical parameters with SUV values and kinetic parameters provided additional support for the feasibility of $\mathrm{PCa}$ 
aggressiveness measurement using $\left[{ }^{11} \mathrm{C}\right]$-acetate PET/CT. Correlation of PSA with early SUV $(r=0.50$, $p=0.02)$ and $K_{1}(r=0.48, p=0.03)$ suggests that cancer differentiation from normal tissue can be accomplished by $\left[{ }^{11} \mathrm{C}\right]$-acetate PET/CT kinetic parameters. Similarly, correlation of both early and late SUVs with $\mathrm{V}_{\mathrm{T}}(\mathrm{r}>0.76, \mathrm{p}<0.001)$ and $\mathrm{K}_{1}(\mathrm{r}>0.64$, $\mathrm{p}<0.005)$ signifies the use of SUV as a marker of prostate cancer. However, no significant correlation was noticed between Gleason score and PET parameters.

Previously, Tolbod et al. [41] non-invasively quantified tumor blood flow (TBF) in PCa using $\left[{ }^{15} \mathrm{O}\right]$-water and concluded that $\left[{ }^{15} \mathrm{O}\right]$-water PET can accurately measures TBF and be useful for evaluation of tumor aggressiveness in PCa. Further, a pilot study [42] was conducted to measure and quantify TBF in PCa using [ $\left.{ }^{15} \mathrm{O}\right]-$ water and [ $\left.{ }^{82} \mathrm{Rb}\right]$ PET/CT illustrated not only a good correlation of TBF for both tracers but also a significantly increased uptake of [82 Rb] associated with PCa aggressiveness. These studies quantified increased blood flow in the cancerous region of prostate compared to normal and is also shown in this study $\left(\mathrm{K}_{1}\right)$ using $\left[{ }^{11} \mathrm{C}\right]$-acetate. Further, increased metabolic demand of cancerous region to support tumor growth reflected with increased $\left[{ }^{11} \mathrm{C}\right]$-acetate retention $\left(\mathrm{V}_{\mathrm{T}}\right)$.

The results of the kinetic studies in vitro and in vivo indicate that the biological pathway of $\left[{ }^{11} \mathrm{C}\right]$-acetate in prostate cancer cell was dominated by the uptake and retention most probably indicating the involvement of $\left[{ }^{11} \mathrm{C}\right]$-acetate in lipid synthesis. As mentioned above the lipid synthesis extent is an indication of prostate cancer aggressiveness. The $\left.{ }^{[11} \mathrm{C}\right]$-acetate uptake and retention pattern in the cell experiments, and the correlation of the $\mathrm{K}_{1}$ and $\mathrm{V}_{\mathrm{T}}$ parameters with SUVs in the clinical study clearly indicate that $\left[{ }^{11} \mathrm{C}\right]$-acetate/PET has the potential for the estimation of the disease progression measuring the lipid synthesis extension.

Further improvement of the suggested methodology would require: inclusion of high risk aggressive prostate cancer patients to confirm the results attained from this study; introduction of partial volume correction for higher quantification accuracy; and histopathological documentation of a larger patient cohort.

\section{Conclusion}

The single-tissue compartment model enabled generation of parametric images of $\left.{ }^{[11} \mathrm{C}\right]$-acetate kinetics for the visualization of cancer biology. The extraction rate $\left(\mathrm{K}_{1}\right)$ and distribution volume $\left(\mathrm{V}_{\mathrm{T}}\right)$ of $\left[{ }^{11} \mathrm{C}\right]$-acetate were considerably higher in low-to-intermediate risk prostate cancer as compared to normal prostate tissue in patients. These results were confirmed in vitro wherein faster growing PC3 cells showed elevated values of $K_{1}$ and $V_{T}$ as compared to DU145 cells. Thus, $\left[{ }^{11} \mathrm{C}\right]$-acetate/PET demonstrated potential for the measurement of $\mathrm{PCa}$ growth and aggressiveness.

\section{Abbreviations}

PCa: prostate cancer; PSA: prostate specific antigen; FA: fatty acid; FASN: fatty acid synthetase; AceCS: acetyl-CoA synthetase; CT: computed tomography; MRI: magnetic resonance imaging; MRS: magnetic resonance spectroscopy; PET: positron emission tomography; SUV: standardized uptake value; TAC: time activity curve; OSEM: ordered subsets expectation maximization; VOI: volume of interest; ROI: region of interest; CPS: counts per second.

\section{Acknowledgements}

The authors express sincere thanks to the staff at the PET Centre and SciLifeLab pilot facility (SPPP - A SciLifeLab Pilot Facility for Preclinical PET-MRI).

Abstract without in-vitro results was presented at the SNM annual conference 2017 held in Denver, Colorado, USA.

\section{Funding}

This work was supported by the Swedish Cancer Society (CAN2016/835).

\section{Competing Interests}

The authors have declared that no competing interest exists.

\section{References}

1. Torre LA, Bray F, Siegel R, et al. Global cancer statistics, 2012. CA Cancer J Clin. 2015; 65(2): 87-108.

2. Klotz L, Zhang L, Lam A, et al. Clinical Results of Long-Term Follow-Up of a Large, Active Surveillance Cohort With Localized Prostate Cancer. J Clin Oncol. 2010; 28(1): 126-131.

3. Selvadurai ED, Singhera M, Thomas $K$, et al. Medium-term Outcomes of Active Surveillance for Localised Prostate Cancer. Eur Urol. 2013; 64(6): 981-987.

4. Hegde JV, Mulkern R, Panych L, et al. Multiparametric MRI of Prostate Cancer: An Update on State-of-the-Art Techniques and Their Performance in Detecting and Localizing Prostate Cancer. J Magn Reson Imaging. 2013; 37(5): 1035-1054

5. Flavin R, Zadra G, and Loda M. Metabolic alterations and targeted therapies in prostate cancer. J Pathol. 2011; 223(2): 283-94.

6. Hanahan D and Weinberg RA. Hallmarks of Cancer: The Next Generation. Cell. 2011; 144(5): 646-674.

7. Spick C, Herrmann K, and Czernin J. Evaluation of Prostate Cancer with 11C-Acetate PET/CT. J Nucl Med. 2016; 57(Suppl 3): S30-S37.

8. Soloviev D, Fini A, Chierichetti F, et al. PET imaging with 11C-acetate in prostate cancer: a biochemical, radiochemical and clinical perspective. Eur J Nucl Med Mol Imaging. 2008; 35(5): 942-9.

9. Sciacca RR, Akinboboye O, Ling Chou R, et al. Measurement of Myocardial Blood Flow with PET Using 1-11C-Acetate. J Nucl Med. 2001; 42(1): 63-70.

10. Lear JL. Relationship Between Myocardial Clearance Rates of Carbon-11-Acetate-Derived Radiolabel and Oxidative Metabolism: Physiologic Basis and Clinical Significance. J Nucl Med. 1991; 32(10): 1957-1960. 
11. Nesterov SV, Turta O, Han C, et al. C-11 acetate has excellent reproducibility for quantification of myocardial oxidative metabolism. Eur Heart J Cardiovasc Imaging. 2015; 16(5): 500-506.

12. Sörensen J, Valind S, and Andersson LG. Simultaneous quantification of myocardial perfusion, oxidative metabolism, cardiac efficiency and pump function at rest and during supine bicycle exercise using 1-11C-acetate PET - a pilot study. Clin Physiol Funct Imaging. 2010; 30(4): 279-284.

13. $\mathrm{Ng} \mathrm{CK}$, Huang SC, Schelbert HR, et al. Validation of a model for [1-11C]acetate as a tracer of cardiac oxidative metabolism. Am J Physiol. 1994; 266(4): H1304-H1315.

14. Gropler RJ, Siegel BA, and Geltman EM. Myocardial Uptake of Carbon-11-Acetate as an Indirect Estimate of Regional Myocardial Blood Flow. J Nucl Med. 1991; 32(2): 245-251.

15. Yoshii $Y$, Furukawa T, Oyama N, et al. Fatty acid synthase is a key target in multiple essential tumor functions of prostate cancer: uptake of radiolabeled acetate as a predictor of the targeted therapy outcome. PLoS One. 2013; 8(5): e64570.

16. Yoshimoto M, Waki A, Yonekura $\mathrm{Y}$, et al. Characterization of acetate metabolism in tumor cells in relation to cell proliferation: acetate metabolism in tumor cells. Nucl Med Biol. 2001; 28(2): 117-22.

17. Vāvere $\mathrm{AL}$, Kridel SI, Wheeler FB, et al. 1-11C-Acetate as a PET Radiopharmaceutical for Imaging Fatty Acid Synthase Expression in Prostate Cancer. J Nucl Med. 2008. 49(2): 327-334

18. Yoshii Y, Waki A, Furukawa T, et al. Tumor uptake of radiolabeled acetate reflects the expression of cytosolic acetyl-CoA synthetase: implications for the mechanism of acetate PET. Nucl Med Biol. 2009; 36(7): 771-777.

19. Leisser A, Prusha K, Ubl P, et al. Evaluation of fatty acid synthase in prostate cancer recurrence: SUV of [(11) C]acetate PET as a prognostic marker. Prostate. 2015; 75(15): 1760-7.

20. Oyama N, Akino H, Kanamaru H, et al. 11C-Acetate PET Imaging of Prostate Cancer. J Nucl Med. 2002; 43(2): 181-186.

21. Kotzerke J, Volkmer BG, Glatting G, et al. Intraindividual comparison of $[11 C]$ acetate and $[11 C]$ choline PET for detection of metastases of prostate cancer. Nuklearmedizin. 2003; 42(1): 25-30.

22. Regula N, Haggman M, Johansson S, et al. Malignant lipogenesis defined by 11C-acetate PET/CT predicts prostate cancer-specific survival in patients with biochemical relapse after prostatectomy. Eur J Nucl Med Mol Imaging. 2016; 43(12): 2131-2138.

23. Sun A, Johansson S, Turesson I, et al. Imaging Tumor Perfusion and Oxidative Metabolism in Patients With Head-and-Neck Cancer Using 1- [11C]-Acetate PET During Radiotherapy: Preliminary Results. Int J Radiat Oncol Biol Phys. 2012; 82(2): 554-560.

24. Schiepers C, Hoh CK, Nuyts J, et al. 1-11C-acetate kinetics of prostate cancer. J Nucl Med. 2008; 49(2): 206-15.

25. Le Bars D, Malleval M, Bonnefoi F, et al. Simple synthesis of [1-11C]acetate. J Label Compd Radiopharm. 2006; 49(3): 263-267.

26. Pike VW, Eakins MN, Allan RM, et al. Preparation of [1-11C]acetate-An agent for the study of myocardial metabolism by positron emission tomography. Int J Appl Radiat Isot. 1982; 33(7): 505-512.

27. Björke $\mathrm{H}$, and Andersson K. Measuring the affinity of a radioligand with its receptor using a rotating cell dish with in situ reference area. Appl Radiat Isot. 2006; 64(1): 32-37.

28. Björke $\mathrm{H}$, and Andersson $\mathrm{K}$. Automated, high-resolution cellular retention and uptake studies in vitro. Appl Radiat Isot. 2006; 64(8): 901-905.

29. Daouacher $\mathrm{G}$, Von Below $\mathrm{K}$, Gestblom $\mathrm{C}$, et al. Laparoscopic extended pelvic lymph node (LN) dissection as validation of the performance of [11C]-acetate positron emission tomography/computer tomography in the detection of LN metastasis in intermediate- and high-risk prostate cancer. BJU Int. 2016; 118(1): $77-83$.

30. Haseebuddin M, Dehdashti F, Siegel BA, et al. 11C-acetate PET/CT before radical prostatectomy: nodal staging and treatment failure prediction. J Nucl Med. 2013; 54(5): 699-706.

31. Oyama N, Miller TR, Dehdashti F, et al. 11C-Acetate PET Imaging of Prostate Cancer: Detection of Recurrent Disease at PSA Relapse. J Nucl Med. 2003; 44(4): 549-555.

32. Spick C, Polanec SH, Mitterhauser M, et al. Detection of Bone Metastases Using 11C-Acetate PET in Patients with Prostate Cancer with Biochemical Recurrence. Anticancer Res. 2015; 35(12): 6787-91.

33. Albrecht S, Buchegger F, Soloviev D, et al. (11)C-acetate PET in the early evaluation of prostate cancer recurrence. Eur J Nucl Med Mol Imaging. 2007; 34(2): 185-96.

34. Muramoto $\mathrm{S}$, Uematsu $\mathrm{H}$, Sadato $\mathrm{N}$, et al $\mathrm{H}(2)$ (15)0 positron emission tomography validation of semiquantitative prostate blood flow determined by double-echo dynamic MRI: a preliminary study. J Comput Assist Tomogr. 2002; 26(4): 510-4.

35. Cho E, Chung DJ, Yeo DM, et al. Optimal cut-off value of perfusion parameters for diagnosing prostate cancer and for assessing aggressiveness associated with Gleason score. Clin Imaging. 2015; 39(5): 834-840.

36. Pulukuri SM, Gondi CS, Lakka SS, et al. RNA interference-directed knockdown of urokinase plasminogen activator and urokinase plasminogen activator receptor inhibits prostate cancer cell invasion, survival, and tumorigenicity in vivo. J Biol Chem. 2005; 280(43): 36529-40.

37. Lindner $\mathrm{O}$, Sorensen $\mathrm{J}$, Vogt $\mathrm{J}$, et al. Cardiac efficiency and oxygen consumption measured with 11C-acetate PET after long-term cardiac resynchronization therapy. J Nucl Med. 2006; 47(3): 378-83.
38. Hussain $\mathrm{R}$, Kudo $\mathrm{T}$, Tsujikawa $\mathrm{T}$, et al. Validation of the calculation of the clearance rate constant $(\mathrm{k}(\mathrm{mono}))$ of $[(11) \mathrm{C}]$ acetate using parametric $\mathrm{k}(\mathrm{mono})$ image for myocardial oxidative metabolism. Nucl Med Biol. 2009; 36(8): 877-82.

39. Ristow M. Oxidative metabolism in cancer growth. Curr Opin Clin Nutr Metab Care. 2006; 9(4): 339-45.

40. Hansson NHS, Sorensen J, Harms HJ, et al. Myocardial Oxygen Consumption and Efficiency in Aortic Valve Stenosis Patients With and Without Heart Failure. J Am Heart Assoc. 2017; 6(2): e004810.

41. Tolbod LP, Nielsen MM, Pedersen BG, et al. Non-invasive quantification of tumor blood flow in prostate cancer using (15)O-H(2)O PET/CT. Am J Nucl Med Mol Imaging. 2018; 8(5): 292-302.

42. Jochumsen MR, Tolbod LP, Pedersen BG, et al. Quantitative Tumor Perfusion Imaging with (82) Rb PET/CT in Prostate Cancer: Analytic and Clinical Validation. J Nucl Med. 2019; 60(8): 1059-1065. 